\title{
Discovery and description of the first human Retro-Giant
}

\section{virus [version 1; peer review: 1 approved with reservations]}

\author{
Elena Angela Lusi (iD1, Federico Caicci (iD)2 \\ 1St Vincent Health Care Group, University College Dublin, Dublin, Ireland \\ 2Department of Biology-Electron Microscopy Unit, University of Padua, Padova, Italy
}

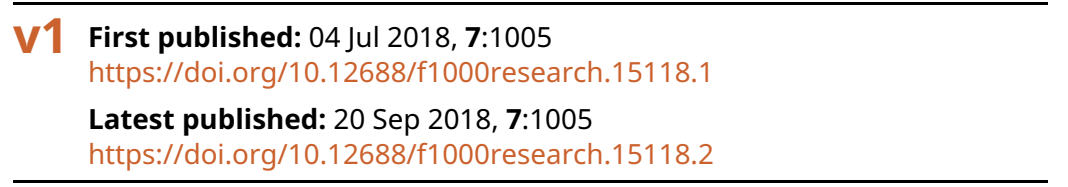

\section{Abstract}

Background: Robert Gallo reported the first human retrovirus HLTV in 1980. What we report here is the first human giant virus, Mimiviruslike, with a retroviral core.

Methods: The isolation of human giant viruses from human T cells Leukaemia was performed on $25 \%$ sucrose gradient. The purified viral pellet was examined using electron microscopy (EM), after immunolabelling with anti-FeLV gag p27 moAb, used for its ability to bind conserved epitopes among different mammalian retroviruses. RNA extracted from the viral particles was amplified with the Pan Retrovirus PCR technique that targets the most conserved VLPQG and YMDD in the Pol region of different retroviruses. The amplified genes were sequenced and analyzed with molecular phylogenetic tests. Results: EM showed the presence of $\sim 400 \mathrm{~nm}$ giant viruses, mimivirus-like, specifically labelled by anti-FeLV gag p27 Ab. RNA extracted from the particles contained retroviral genes. Molecular phylogenetic analyses of $150 \mathrm{bp}$ amplicon product, compared with the same size amplicons of the Pol gene of diverse retroviruses, showed that the retro-giant viruses are a distinct branch, missing from the current classification of retroviruses.

Conclusions: Although sharing some of the morphological features with Mimiviruses, this human giant virus differs substantially from environmental DNA-giant viruses isolated so far, in that it manifests a unique mammalian transforming retroviral core and T cell tropism. The virus should not be confused with a classic human retrovirus nor even a large human retrovirus, but an ancestral human giant virus, mimivirus-like, with a mammalian retroviral core. Certainly, the oncogenic potential of the viral particle and its T cell tropism is of concern and further studies are needed to clarify the role of this giant virus in human diseases and evolution of archetypal retroviruses.

\section{Keywords}

Retroviruses, Mimiviruses, Giant Viruses, anti-FeLV gag, human T cell Leukaemia, Retro-Giant Virus

\section{Open Peer Review}

Approval Status

\section{version 2}

(revision)

20 Sep 2018

version 1

04 Jul 2018

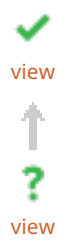

1. Didier Raoult, Aix-Marseille Université,

URMITE, UM63, CNRS7278, IRD198, Inserm

1095, Marseille, France

Any reports and responses or comments on the article can be found at the end of the article. 
Corresponding author: Elena Angela Lusi (elenaangelalusi@yahoo.it)

Author roles: Lusi EA: Conceptualization, Data Curation, Formal Analysis, Funding Acquisition, Investigation, Methodology, Project Administration, Resources, Supervision, Validation, Visualization, Writing - Original Draft Preparation, Writing - Review \& Editing; Caicci F: Methodology

Competing interests: No competing interests were disclosed.

Grant information: This work was supported in part by St Vincent Health Care Group of Dublin, Ireland.

Copyright: ( $\odot 2018$ Lusi EA and Caicci F. This is an open access article distributed under the terms of the Creative Commons Attribution License, which permits unrestricted use, distribution, and reproduction in any medium, provided the original work is properly cited. Data associated with the article are available under the terms of the Creative Commons Zero "No rights reserved" data waiver (CC0 1.0 Public domain dedication).

How to cite this article: Lusi EA and Caicci F. Discovery and description of the first human Retro-Giant virus [version 1; peer review: 1 approved with reservations] F1000Research 2018, 7:1005 https://doi.org/10.12688/f1000research.15118.1

First published: 04 Jul 2018, 7:1005 https://doi.org/10.12688/f1000research.15118.1 


\section{Introduction}

Our previous paper described the presence of unusual Mimiviruses-like structures in human tissues ${ }^{1}$. Like Mimiviruses ( 450 nm giant viruses found in the amoebas), these human structures had the ability to retain Gram staining, and mass spectrometry revealed the presence of histone peptides that had the same footprints as giant viruses ${ }^{2-9}$. However, the human giant virus-like structures displayed a distinct and unique mammalian retroviral antigenicity.

Our initial discovery in human tissues presented the conundrum of whether the structures were giant viruses with a retroviral nature or cellular components having a viral footprint. The distinction between the virus and the cells was blurred. The most difficult part to explain arose from the unique mammalian retroviral antigenicity associated with the human Mimivirus-like structures.

There was only one possibility to solve the dilemma: isolate the viruses (if really present) and verify if they contain genetic material. Consequently, in the present study we chose the traditional way of isolating virus using a sucrose gradient, following the same protocols and steps described by Prof Robert Gallo in his discovery of the first human retrovirus, human T-lymphotropic virus (HTLV) ${ }^{10}$.

The gigantic dimension of our viral particle excluded it from the orthodox understanding of retroviruses but simultaneously presented the antipodean challenge to establish if this giant virus's retroviral properties signified the discovery of the first human Retro-Giant virus.

In this manuscript, we report the isolation of a human giant virus, mimivirus-like, with a retroviral core from human $\mathrm{T}$ cell acute lymphoblastic leukaemia, and the various experiments on the purified giant virus, including immunogold electron microscopy, nucleic acid extraction, reverse transcriptase assay, genetic sequencing and phylogenetic analyses.

The experiments, validated by independent operators kept blind, determined the retroviral nature of a human giant virus with associated viral factory that is ancestral to archetypal retroviruses.

\section{Methods}

Purification of human giant viruses on sucrose gradient $10^{8}$ human $\mathrm{T}$ cell leukaemia (HPB-ALL, DSMZ, Germany), grown at $37^{\circ} \mathrm{C}$ in RPMI-1640, $10 \%$ fetal bovine serum and $2 \mathrm{mM}$ L-glutamine, were centrifuged at $1,500 \mathrm{rpm} \mathrm{g}$ for 5 minutes at $4^{\circ} \mathrm{C}$. The cell pellet was washed with $1 x$ PBS. The cells were lysed (vortexed) with $2.5 \mathrm{ml}$ PBS in the presence of $25 \mu$ of protease inhibitor cocktail (Abmgood, Richmond BC, Canada). Cell suspension was vortexed and incubated a $4{ }^{\circ} \mathrm{C}$ for 30 minutes. Cell lysis was monitored using a phase contrast light microscope. The resulting crude extract was centrifuged at 3,000 rpm for 5 minutes. The pellet containing the cellular nuclei was discharged.

The resulting supernatant was collected and slowly dripped over $9 \mathrm{ml}$ of a $35-30-25 \%$ sucrose gradient (Sigma, Milan, Italy) and centrifuged at $10,000 \mathrm{rpm}$ for $5 \mathrm{~h}$ in a $15 \mathrm{ml}$ Corex glass centrifuge tubes (Fisher Scientific, Dublin, Ireland). Once a visible white disk, corresponding to $25 \%$ sucrose fraction, was observed, the viral pellet was collected after centrifugation at $14,000 \mathrm{rpm}$ for $30 \mathrm{~min}$, at $4^{\circ} \mathrm{C}$.

\section{RNA extraction from the giant viral particles}

The viral pellet was lysed with $1 \mathrm{ml}$ of RNA-XPress Reagent (Himedia, Mumbai, India), a monophasic solution of phenolguanidine thiocyanate, and incubated at room temperature (RT) for 5 minutes. This was followed by the addition of $200 \mu \mathrm{L}$ chloroform, vortexing for $15 \mathrm{sec}$ and incubation at RT for $10 \mathrm{~min}$. The organic and aqueous phases were separated by centrifuging the sample at $11,000 \mathrm{rpm}$ for 15 minutes at $4^{\circ} \mathrm{C}$. The aqueous phase, containing RNA, was harvested and precipitated with $600 \mu \mathrm{l}$ of isopropyl alcohol and glycogen. After incubation for $1 \mathrm{~h}$ at $20^{\circ} \mathrm{C}$, RNA was pelleted by centrifugation at $11,000 \mathrm{rpm}$ for 10 minutes. The RNA pellet was washed with $75 \%$ of ethanol, air dried and resuspended in RNase free $\mathrm{H}_{2} \mathrm{O}$ (Himedia). One aliquot was utilized for concentration determination in a MaestroNano Spectrophotometer (Maestrogen Inc, Hsinchu City, Taiwan).

\section{cDNA synthesis}

$1 \mu \mathrm{g}$ of total RNA was utilized for cDNA synthesis using EasyScript cDNA Synthesis Kit (Abmgood) according to the manufacturer's instructions. Briefly, $20 \mu \mathrm{l}$ of reaction contained 200 units of reverse transcriptase, $0.5 \mu \mathrm{M}$ of random primers, 20 units of ribonuclease inhibitors, $500 \mu \mathrm{M}$ dNTP. The reaction was carried out at $25^{\circ} \mathrm{C}$ for $10 \mathrm{~min}$, then at $42^{\circ} \mathrm{C}$ for $50 \mathrm{~min}$.

\section{Pan-retrovirus PCR from RNA of the human giant virus}

We performed a Pan-retrovirus PCR from the RNA extracted from the giant viruses. To amplify a segment of the Pol gene, we used degenerate primers targeting a conserved region, of approximately $140 \mathrm{bp}$, between the most conserved domain VLPQG and YMDD in the Pol gene of retroviruses. The oligonucleotide primers and conditions were derived from those described by Tuke et al. ${ }^{11}$. The first PCR mixture was performed by amplifying $1 \mu \mathrm{l}$ of the double-stranded cDNA reaction with the following reagents: $1 \mu \mathrm{M}$ primer PAN-UO (5'-CTT GGATCCTGGAAAGTGCTAAGCCCAC-3') and $1 \mu \mathrm{M}$ primer PAN-D1 (5'-CTCAAGCTTCAG CGATGGTCATCCATCGTA-3') with 1.25 unit of thermostable DNA polymerase (Precision DNA Polymerase, Abmgood). The above mixture was brought to a final volume of $25 \mu$ l with a PCR mix (Abmgood, Richmond, BC, Canada) containing $0.2 \mathrm{mM}$ dNTPs/ $2.0 \mathrm{mM} \mathrm{MgCl} 2$ in $1 \mathrm{X}$ PCR reaction buffer. The PCR was performed in a Thermal Cycler (GET3X Triple Block Thermal Cycler, Bio-Gener, China) using the following conditions: 1 cycle of $95^{\circ} \mathrm{C}$ for 10 minutes; 35 cycles of $95^{\circ} \mathrm{C}$ for 1 minute, $34^{\circ} \mathrm{C}$ for 1 minute, $72^{\circ} \mathrm{C}$ for 1 minute; 1 cycle of $72^{\circ} \mathrm{C}$ for 10 minutes.

In total, $1 \mu$ of this reaction was re-amplified in a seminested reaction using the PAN-UI (5' CTTGGATCCAG TGTCTAGCCCACAAGGG-3') primer in combination with PAND1. Conditions for the semi-nested PCR were: 1 cycle of 10 minutes at $95^{\circ} \mathrm{C} ; 40$ cycles of $95^{\circ} \mathrm{C}$ for 1 minute, $45^{\circ} \mathrm{C}$ for 30 seconds, $72^{\circ} \mathrm{C}$ for 1 minute; 1 cycle of $72^{\circ} \mathrm{C}$ for 10 minutes. 
A $10-\mu 1$ aliquot of the resulting PCR product was analyzed after electrophoresis on a $2.5 \%$ MS8 agarose gel (Laboratorios Conda, Madrid, Spain). The amplified bands were recovered from the gel with UltraPrep Agarose Gel Extraction Kit (AHN Biotechnologie $\mathrm{GmbH}$, Nordhausen, Germany) according to the manufacturer's instructions. Briefly, the DNA was excised from the agarose gel and weighted. Three volumes of buffer (volume: weight of the excised gel band size) was added and the mixture was incubated at $50^{\circ} \mathrm{C}$ for 10 minutes. The DNA was bound to a column and centrifuged at 13,000 rpm for 1 minute. After awash with $700 \mu \mathrm{l}$ of washing buffer, the DNA was recovered from the column with $50 \mu \mathrm{l}$ of elution buffer.

\section{Sanger sequencing and molecular phylogenetic analyses} DNA sequencing was performed on an ABI 3500 Automatic Sequencer (Applied Biosystems, Foster City, CA, USA) using Big Dye Terminator v3.1 (Applied Biosystems).

Molecular phylogenetic analyseswere made at BMR Genomics Institute (Padua, Italy). Our sequences were aligned against other retroviral viral sequences. Sequence accession numbers used in the alignment between $150 \mathrm{bp}$ segment from retro- giant viruses with equivalent VPLP-YMDD Polregion (RT) of different retroviruses, amplified with the same Pan Retrovirus-PCR, are reported in Dataset $1^{12}$. For the phylogenetic analysis of the $400 \mathrm{bp}$ amplicon, retroviral sequences and accession numbers are displayed in Dataset $2^{13}$.

Phylogenetic tree for the 150bp VLPQ-YMDD interval was made using Phylogeny.fr (A La Carte Mode). T-Coffee was used for multiple alignment, Gblocks v $0.91 \mathrm{~b}$ for alignment curation, PhyML 3.1 for phylogeny and TreeDyn 198.3 for tree drawing. A non-parametric, Shimodaira-Hasegawa-like approximate Likelihood-Ratio branch test (SH-like aLTR) was used as a statistical test.

For the 400 bp amplicon, phylogenetic tree was made using Phylogeny.fr. Muscle v3.8.31 was used for multiple alignment, Gblocks v 0.91b for alignment curation, PhyML 3.1 for phylogeny and TreeDyn 198.3for tree drawing. A non-parametric, Shimodaira-Hasegawa-like approximate Likelihood-Ratio branch test (SH-like aLTR), default HKY85, was used as a statistical test.

Dataset $1.150 \mathrm{bp}$ amplicon alignment against other VLPQGYMDD Pol sequences of different retroviruses

http://dx.doi.org/10.5256/f1000research.15118.d208073

Dataset 2. 400bp amplicon sequence and its alignment against other retroviral families

http://dx.doi.org/10.5256/f1000research.15118.d208074

Electron microscopy (EM) immunogold of viral particles

$25 \mu \mathrm{l}$ of the $25 \%$ sucrose isolated viral pellet was placed on Holey Carbon film on Nickel 400 mesh. The grids were treated for 30 minutes at room temperature with the primary monoclonal antibody (moAb) anti-Feline Laeukemia Virus p27gag (catalog number, PF12J-10A; Custom Monoclonals International, West Sacramento, CA, USA) and subsequently with a secondary anti-mouse gold conjugated antibody (BB international anti-mouse $\operatorname{IgG} 15 \mathrm{~nm}$ gold conjugate; catalog number, EM.GMHL15, Batch 4838). After staining with $1 \%$ uranyl acetate, the sample was observed with a Tecnai G2 (FEI) (Thermo Fisher) transmission electron microscope, operating at $100 \mathrm{kV}$. Images were captured with a Veleta (Olympus Soft Imaging System) digital camera.

\section{Gram positive stain of the giant viral particles}

Gram positive staining of purified human giant viruses was performed with Colour Gram 2 Biomerieux kit, following the manufactures instructions. Before staining, slides were heated fixed 3-4 times through the Bunsen burner flame.

\section{Reverse transcriptase (RT) assay of the human giant viruses}

After sucrose gradient isolation, the viral pellet was lysed in $20 \mu \mathrm{l}$ of $20 \mathrm{mM}$ Tris-HCL pH7.5, $100 \mathrm{mM} \mathrm{NaCl}, 0.1 \mathrm{mM}$ EDTA, $1 \mathrm{mM}$ DTT, $50 \%$ (v/v) glicerol, $0.25 \%$ Triton X-100 (Sigma). To test the ability of the human giant viruses to retro-transcribe, $10 \mu \mathrm{l}$ of the viral lysate, instead of a reverse transcriptase enzyme, were used to retro-transcribe $1 \mu \mathrm{g}$ of total RNA from Human Liver Total RNA (ThermoFisher Scientific, Waltham, MA, USA). The reverse transcriptase reaction for the viral pellet was carried out with random primers using a commercial kit (EasyScript cDNA Synthesis kit; Abmgood), deprived of the supplied reverse transcriptase enzyme. The reverse transcriptase reaction was carried at $25^{\circ} \mathrm{C}$ for 10 minutes, then at $42^{\circ} \mathrm{C}$ for 50 minutes. The reaction was stopped by heating at $85^{\circ} \mathrm{C}$ for 5 minutes. The viral reverse transcriptase activity was compared to positive controls where a commercial RT enzyme was included (EasyScript RTase; Amgood).

After the reverse transcription, $2 \mu \mathrm{l}$ of the obtained single stranded cDNA was further amplified in presence of $10 \mathrm{pmol}$ of primers for GAPDH, 1.25 units of thermostable DNA polymerase (Precision DNA Polymerase; Abmgood), $0.2 \mathrm{mM}$ dNTPs/ $2.0 \mathrm{mM} \mathrm{MgCl} 2$ in $1 \mathrm{X}$ PCR buffer in a final volume of $25 \mu \mathrm{l}$. PCR conditions were: 1 cycle of $95^{\circ} \mathrm{C}$ for 5 minutes; 40 cycles of $94^{\circ} \mathrm{C}$ for 1 minute, $58^{\circ} \mathrm{C}$ for 1 minute, $72^{\circ} \mathrm{C}$ for 1 minute; 1 cycle of $72^{\circ} \mathrm{C}$ for 5 minutes. $20 \mu \mathrm{l}$ of the PCR reaction was loaded on a $1 \%$ agarose gel for electrophoresis.

Dataset 3. Uncropped and unedited blots

http://dx.doi.org/10.5256/f1000research.15118.d208075

\section{Results}

Virus purification from acute lymphoblastic $T$ cell leukaemia cells and EM immunogold of the viral particles

Giant viral particles, isolated from human $\mathrm{T}$ cell leukemia (HPB-ALL) cells, formed a white ring on $25 \%$ of sucrose gradient. Only the $25 \%$ fraction was collected. This fraction was pure and did not contain any contamination such as cellular nuclei; the nuclear fraction was discharged in the first step of 
differential centrifugation, before layering onto the sucrose gradient.

EM immunogold of the viral pellet depicted giant viral particles $(\sim 400 \mathrm{~nm})$ that were specifically marked by an anti-Feline Leukaemia virus core p27 gag moAb (Figure 1A). The purified human giant viruses retained the Gram stain, like Mimiviruses in amoebas (Figure 1B).

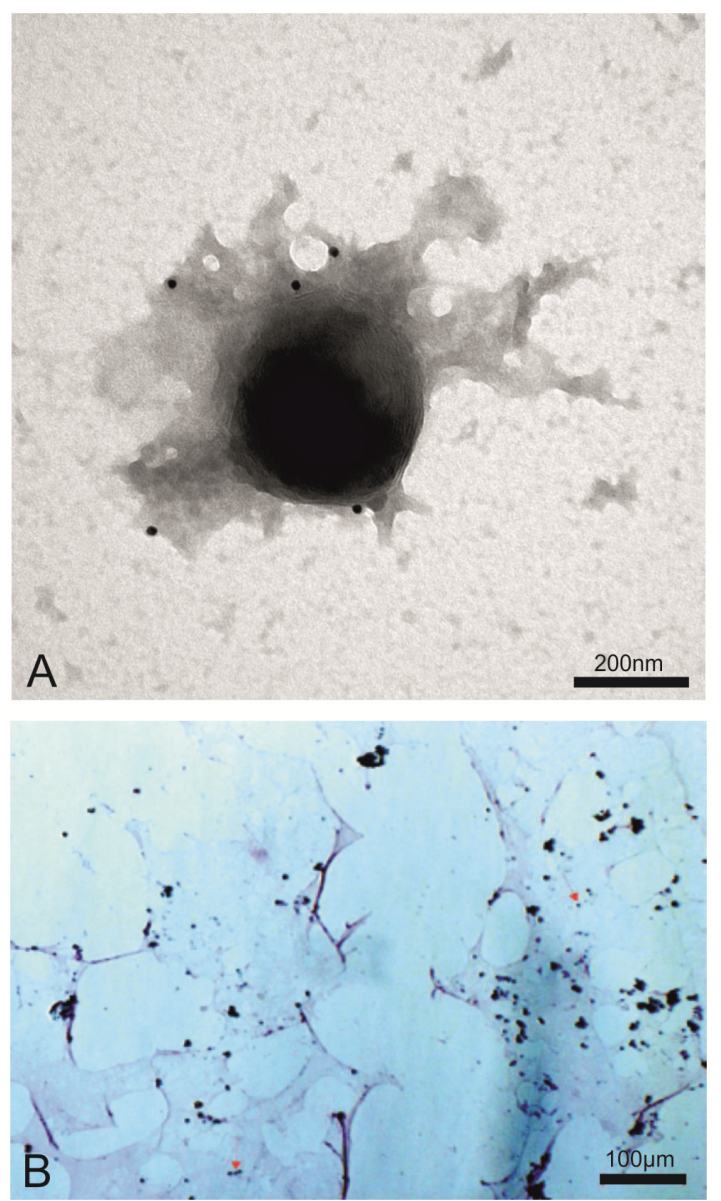

Figure 1. Purified human $400 \mathrm{~nm}$ giant virus labeled with anti FeLV p27 gag moAb. (A) Electron microscopy immunogold shows a $\sim 400 \mathrm{~nm}$ giant virus isolated from human T cell leukemia marked with anti-FeLV p27gag moAb (picture representative of 100 repeats). (B) The same viral pellet during Gram staining shows blue granules that diagnose giant viruses (red arrows indicate some of these, but blue granules can be seen all over the slide). Mimiviruses (giant viruses) were first discovered in the amoebas. The amoebas had Gram positive granules that proved to not be bacteria but giant viruses, mimicking microbes. In the previous manuscript ${ }^{1}$, we showed the presence in human cells of Gram positive giant viral particles associated with viral factories, both sharing the retroviral antigenicity. The viral factories are located inside the cells. What we are presenting here are giant viral particles isolated from human $T$ cell acute lymphoblastic leukaemia by sucrose gradient. This human giant virus differs from amoebas's giant viruses in that it displays the properties of classical retroviruses.
This result confirms our previously published findings where the same anti-Feline Leukaemia virus p27gag moAb specifically marked the giant particles as well as the associated viral factories inside the human cells ${ }^{1}$.

RNA extraction from the giant viral particles, Pan-retrovirus PCR, sequencing and molecular phylogenetic analyses The human giant particles contained retroviral RNA. Identification of the retroviral sequences, extracted from the isolated giant viral particles, was accomplished by PCR with degenerate primers targeting a mostly highly conserved sequence in the reverse transcriptase gene of retroviruses, between two conserved domains VLPQG and YMDD. This amplification approach with degenerate primers was initially described by Tuke et al. and it is called Pan-retrovirus PCR ${ }^{11}$. This PCR system has the ability to detect a $\sim 140 \mathrm{bp}$ amplicon of the Pol gene across many different retroviruses. HIV-1, HTLV-1, Simian D type virus Mason Pfizer monkey virus, Moloney murine leukaemia virus, HERV-W, ERV9 and unknown lymphoma associated retroviruses have been successfully detected with this approach ${ }^{14-16}$. The principles of the technique and the primers are illustrated in Figure 2. We performed the Pan-retrovirus -PCR experiments exclusively on sucrose gradient purified giant viruses that were first examined using EM immunogold.

A predominant band of the expected size of $>150$ bp was amplified from RNA extracted from the human giant viruses (Figure 3, lane 1). Multiple alignments with equivalent and already established Pol region of retroviruses, amplified by the same technique, confirm that our $150 \mathrm{bp}$ amplicon is a Pol-like gene. A molecular phylogenetic analysis based on this region suggests that this amplicon (indicated as RGV) belongs to a distinct evolutionary branch among the whole retroviral families (Figure 4).

Along with the $150 \mathrm{bp}$ band, a $400 \mathrm{bp}$ amplicon was also detected (Figure 3, lane 1). Multiple alignment and phylogenetic analysis showed that the $400 \mathrm{bp}$ band aligns entirely on the human chromosome 7 and clusters with human endogenous retroviruses (HERVs) genes (Figure 5). This finding replicates consolidated reports of almost intact human endogenous retrovirus genomes in chromosome $7^{17-24}$. Additional information is in Dataset 1- Dataset 3.

Phylogenetic tree was made with webserver http://www.phylogeny.fr. Musclev3.8.31 was used for multiple alignment, Gblocks for alignment curation, PhyML for phylogeny and TreeDyn for treedrawing. A non-parametric, Shimodaira-Hasegawa-like approximate Likelihood-Ratio branch test (SH-like aLTR) was used as statistic test.

\section{Reverse transcriptase activity}

The retro-giant viruses has reverse transcriptase activity. $10 \mu$ the lysated viral pellet produced cDNA from an RNA template (Figure 6). 
PCR AMPLIFICATION PRODUCT
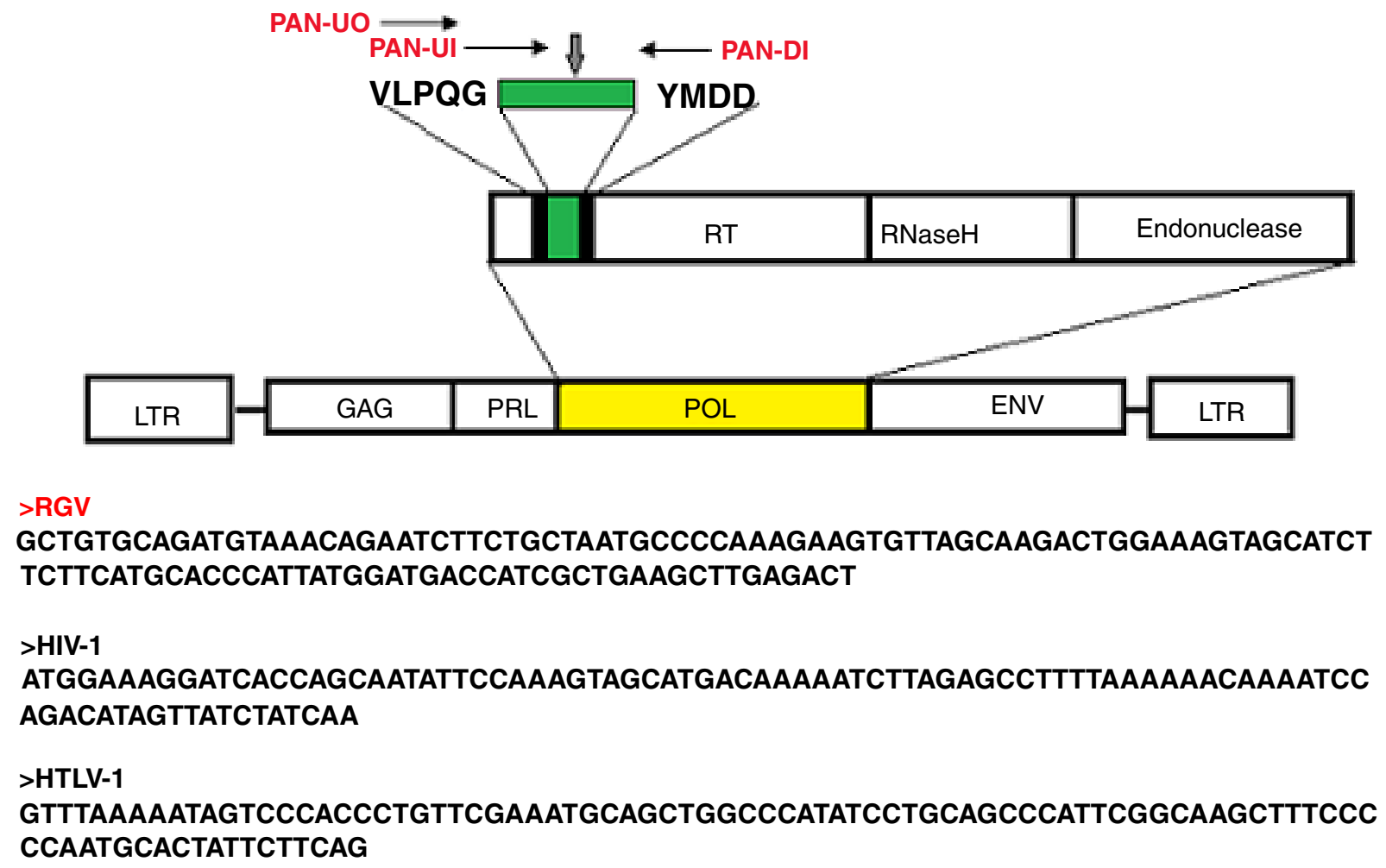

$>$ FRD

TTTCAGAGATAGTCCCCATTTGTTTGGGCAAGCCTTGGCTAGATATTTGCAGGACCTAAGTCTTTATATGGGA GGGCATCTCCTACAG

Figure 2. The Pan-retrovirus PCR approach as described by Tuke et al. ${ }^{11}$. The technique uses degenerate primers capable of amplifying a region in Reverse Transcriptase, between two conserved motifs VLPQ and YMDD in the Pol gene across different retroviruses. The Pol sequence amplified from the human giant viruses is indicated as RGV (bold red). Corresponding same size region of different retroviruses, amplified with the same technique ${ }^{11,14}$, are reported. 

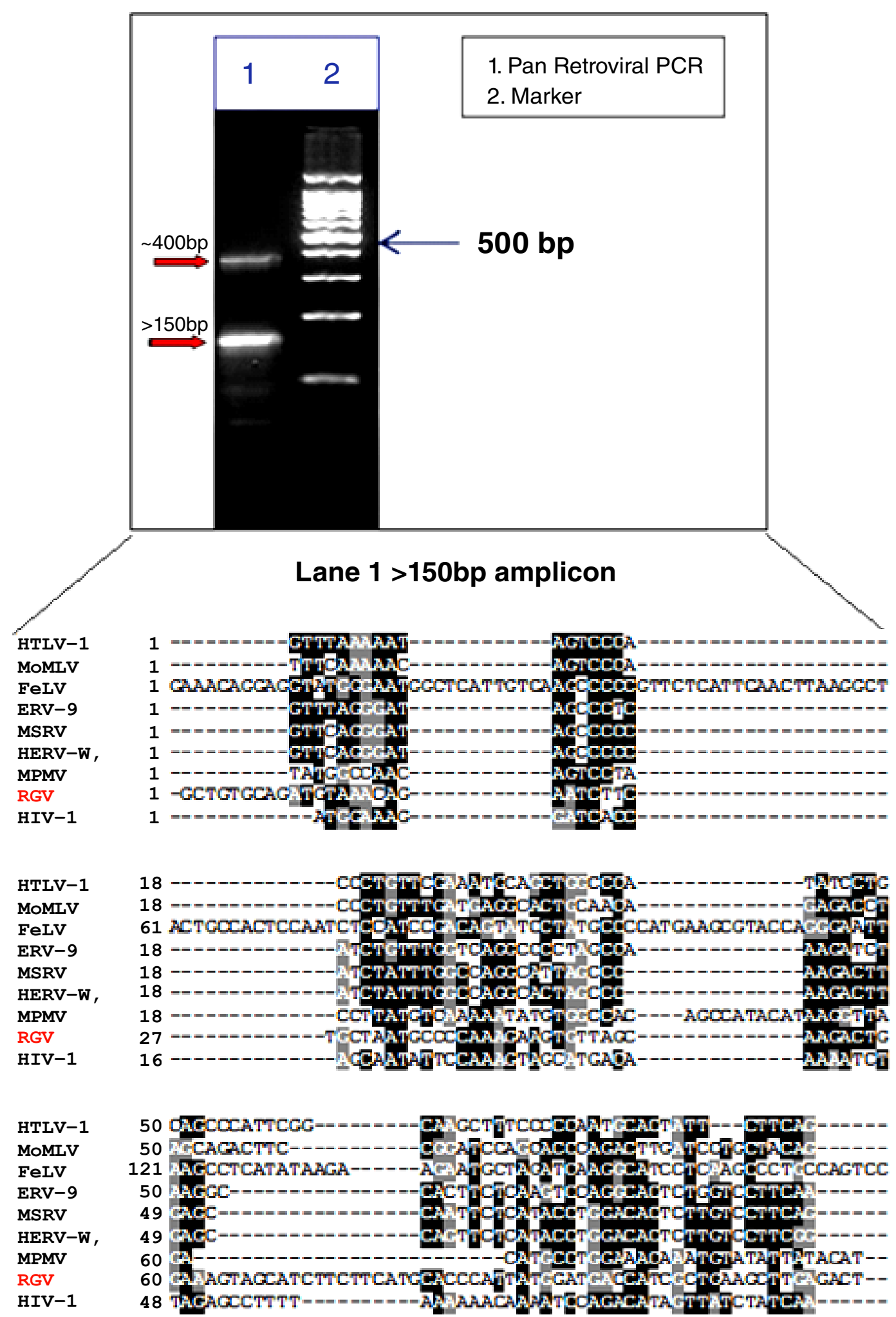

Figure 3. RNA extracted from giant viruses was amplified with a Pan-retrovirus PCR, as described by Tuke et al. ${ }^{11}$. A 400 bp band and $\mathrm{a}>150 \mathrm{bp}$ band were amplified, lane 1 on the agarose gel. Lane 2 is the marker (100-200-300-400-500-600-700-800-900-1000-1500bp). Multiple alignments of our 150bp band (RGV bold red) with equivalent and already established Pol region of retroviruses, amplified by the same technique, confirm that our $150 \mathrm{bp}$ amplicon is a Pol-like gene. 


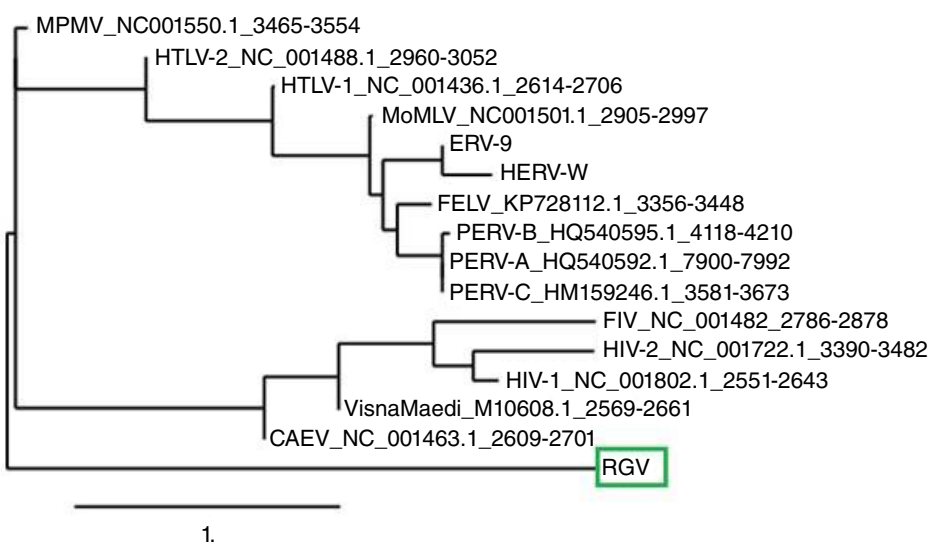

Figure 4. Phylogenetic tree of Pol region between the two conserved motifs VLPQG and YMDD of the reverse transciptase. The RetroGiant Virus (RGV) >150 amplicon (red circle) was analyzed and compared with the same conserved region of other retroviruses. See the Methods section for information on phylogenetic analysis. The RGV amplicon (green box) appears as a new, distinct, ancestral branch.

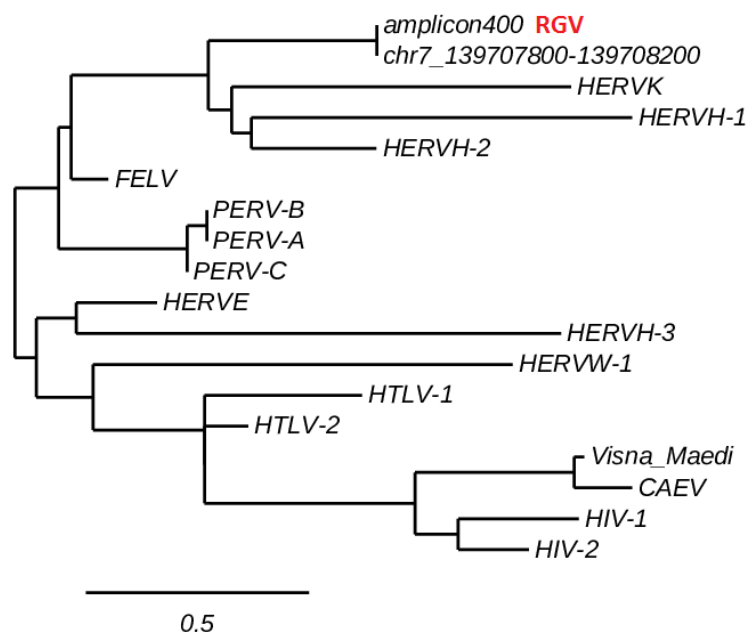

Figure 5. Phylogenetic relationship of the 400 bp amplicon amplified with the Pan-retrovirus PCR from the RNA of the giant viruses. The $\sim 400 \mathrm{bp}$ amplicon aligns entirely on a fragment of the human chromosome 7 and clusters with HERVs. This finding replicates established data of HERVs mapping in the human chromosome 7. See the Methods section and Dataset 2 for information on phylogenetic analysis.
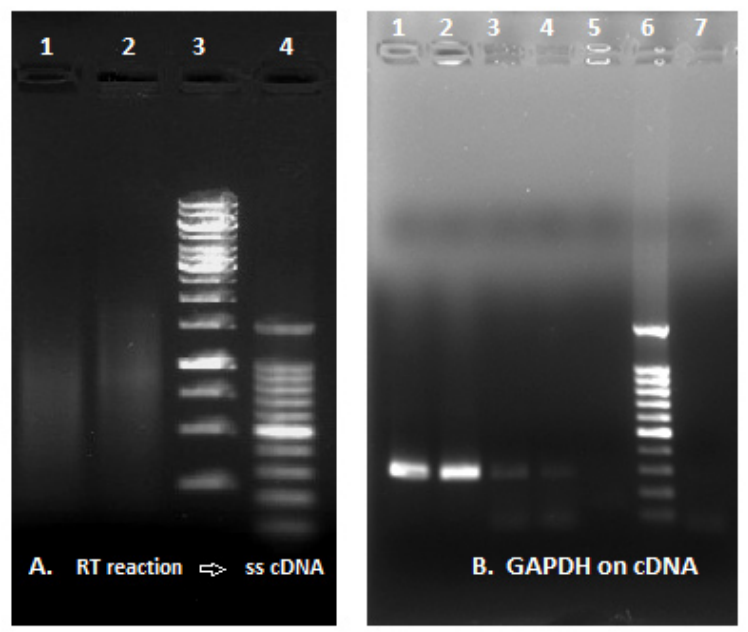

Figure 6. Reverse Transcriptase (RT) activity of the human Retro-Giant viruses. (A) RT reaction and synthesis of ss C-DNA: Lane 1, reaction with a commercial RT enzyme; Lane 2, reaction with viral pellet (reaction without RT enzyme); Lane 3, GeneRuler 1Kb DNA ladder; Lane 4, 100 bp DNA ladder. (B) GAPDH amplification from ss-cDNA template: Lanes 1 and 2, reaction with commercial RT enzyme; Lanes 3 and 4, reaction with the lysated viral pellet; Lane 5, negative control; Lane 6, DNA ladder; Lane 7, additional negative control. 
Summary of results (Figure 7 and Figure 8)

1. The fraction extracted from human $\mathrm{T}$ cell leukaemia cells and purified through $25 \%$ sucrose gradient are human giant viruses with a retroviral core.

2. They have $\sim 400 \mathrm{~nm}$ dimension as shown using EM. The anti FeLV p27 gag antibody labelled the giant viral particles.

3. Pan-retrovirus PCR and molecular phylogenesis confirm the presence in the viral particles of retroviral genes.
4. The Retro-Giant viruses have reverse transcriptase activity.

5. Like giant mimiviruses in the amoebas, the human giant viruses retain Gram staining and they are associated with viral factories, but the substantial difference is their $\mathrm{T}$ tropism and the retroviral core: they are human Retro-Giant viruses (RGV), missing from the current retroviral classification.
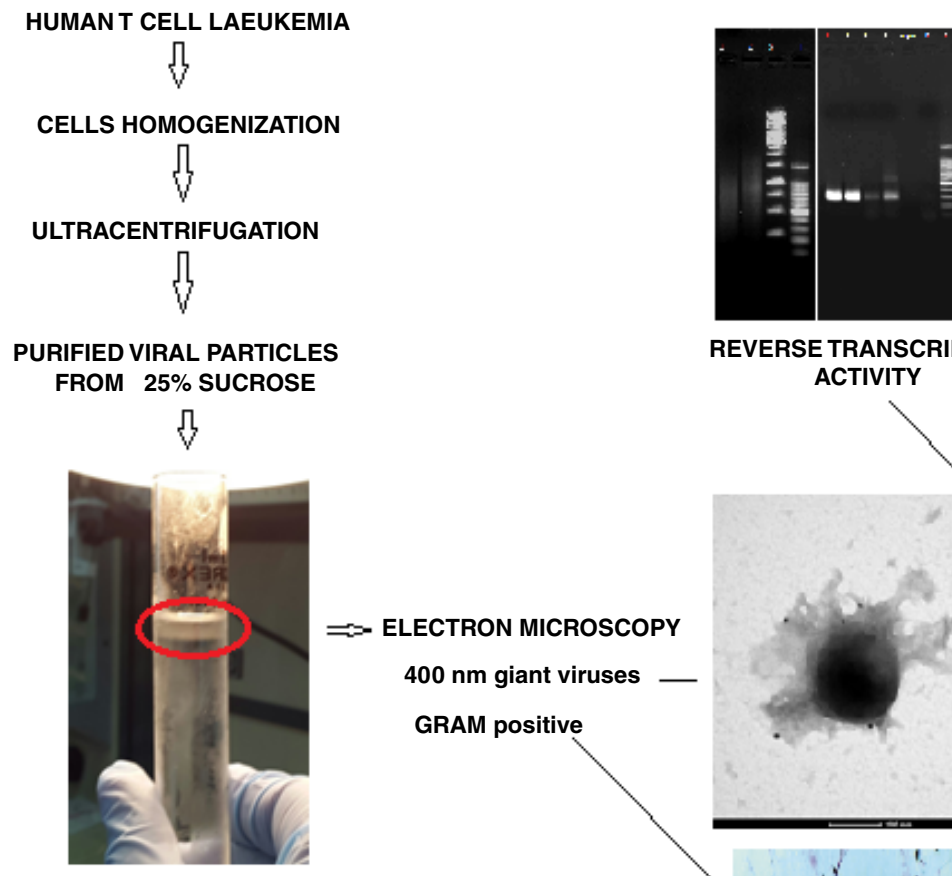

REVERSE TRANSCRIPTASE ACTIVITY

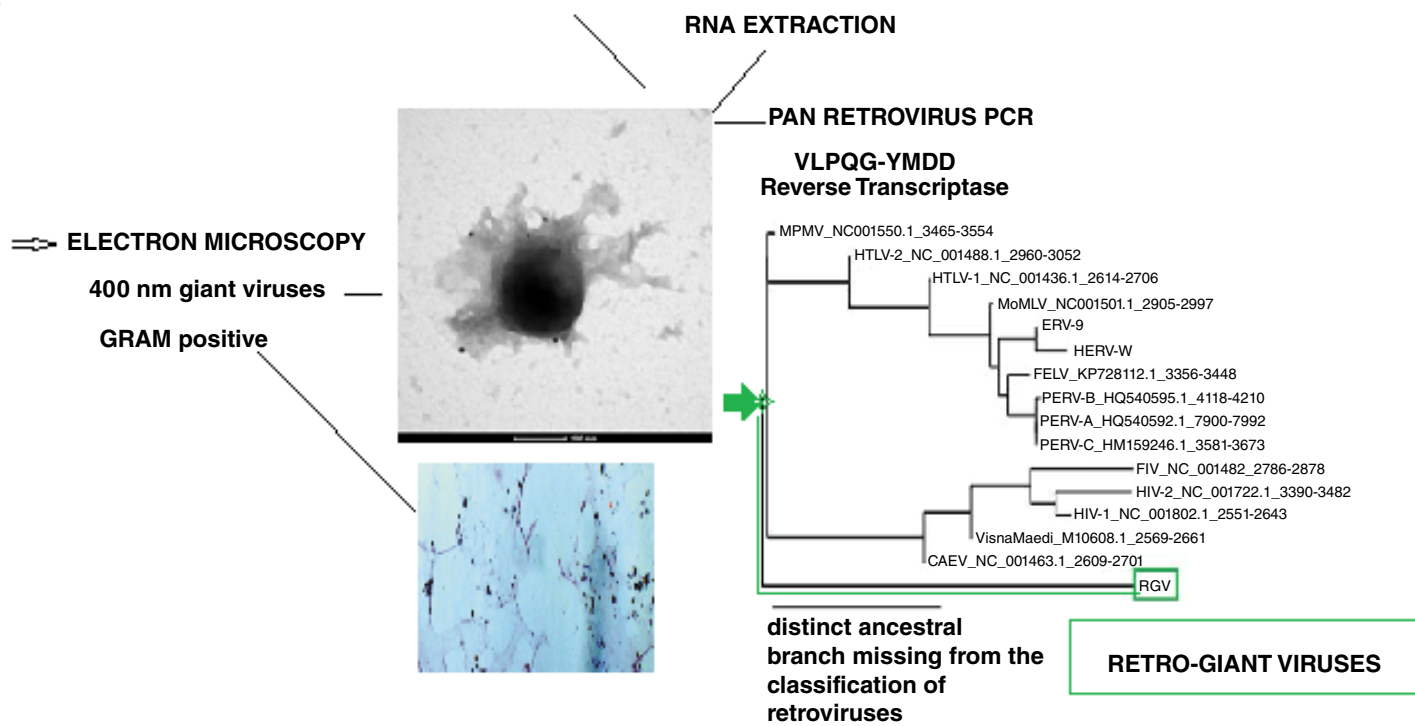

Figure 7. Steps for purification and characterization of human Retro-Giant viruses. Giant viruses were isolated from human leukaemia $\mathrm{T}$ cells on $25 \%$ sucrose gradient (sedimentation fraction of giant viruses in general). Cell nuclei was discharged before layering onto the sucrose. The isolated viral pellet was examined using EM immunogold, which confirmed the presence of $\sim 400$ nm giant viruses with retroviral antigens (anti-FeLV gag). The viral pellet was also stained with the Gram stain. The viral lysate had reverse transcriptase activity. A Pan retroviral PCR of the RNA extracted from the giant viral particles amplified the VLPQ--YMDD region of RT gene. Molecular phylogeny suggests that the Retro-Giant viruses are rare and a new distinct ancestral missing from the current classification of retroviruses. 

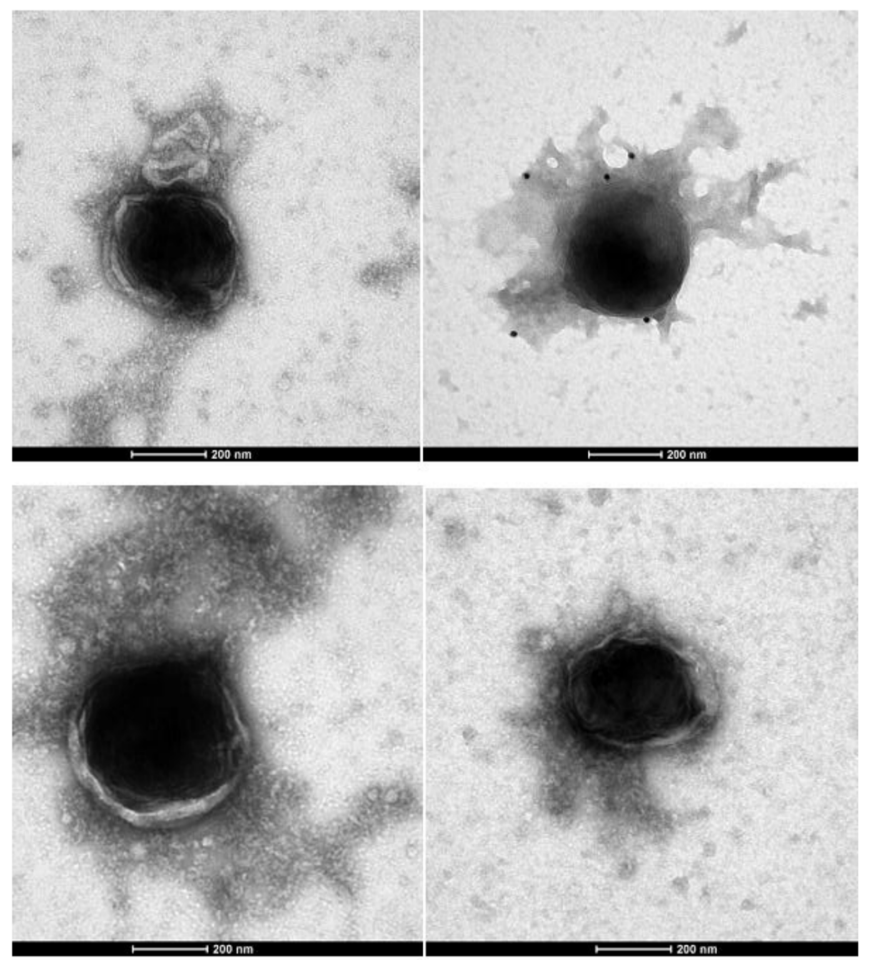

Figure 8. EM of isolated Retro-Giant viruses from human T cell acute lymphoblastic leukaemia by sucrose gradient. These pictures are representative of 100 micrographs. Contact the corresponding author to inspect the entire collection. These human giant viruses have a retroviral antigenicity (positive immunogold with moAbs anti-FeLV retroviral antigens, black dots in the picture), reverse transcriptase activity and amplified segment of the Reverse Transcriptase (Pol gene). The human Retro-Giant viruses retain the Gram stain and inside the cells they are associated to their viral factories, also displaying the retroviral antigenicity ${ }^{1}$.

\section{Discussion}

Robert Gallo reported the first human retrovirus HLTV in 1980. What we report here is the discovery of the first Mimivirus-sized human giant virus with a retroviral core.

In our previous work, conducted initially on human tissues with anti-FeLV gag p27 moAb, EM depicted previously unreported $\sim 400 \mathrm{~nm}$ gigantic particles associated with large aggregates, resembling viroplasms, recognized by anti-FeLVp27 gag $\mathrm{Ab}^{1}$. The particle diameters were more than four times the $100 \mathrm{~nm}$ size expected in retroviruses. These large particles and associated structures discovered in human cells appeared to morphologically parallel previously reported amoebas Mimiviruses (giant viruses and their viral factories) ${ }^{7}$.

Gram positive blue granules that disclosed the existence of giant viruses in the amoeba, similarly detected this newly giant virus in human cells both in our previous study ${ }^{1}$ and current study.

Proteomic analyses suggested the presence of histone H4 variants common to environmental giant DNA viruses, but the striking difference was the unique mammalian retroviral nature of the human giant particles.

However, working on human tissues was confusing and the distinction between the virus and the cells was blurred. How to prove if we were really facing ancestral giant viruses with a retroviral core?

In order to distinguish the giant agent from the human cells, in the present study we isolated the viruses, examined their morphology using EM, extracted their nucleic acid and performed a Pan-retrovirus PCR and Sanger sequencing.

The presence of human Retro-Giant viruses was confirmed step by step. A white ring sedimented on a $25 \%$ of sucrose gradient - the same sedimentation fraction of the giant DNA viruses isolated from the amoebas ${ }^{7}$. EM depicted $\sim 400 \mathrm{~nm}$ giant viral particles that showed the ability to retain the Gram stain, but the striking difference was their unique mammalian retroviral nature. Distinct from the amoebas' Mimiviruses, the viral particles were immuno-labelled with anti FeLV p27gag moAb and they contained retroviral RNA.

RNA extracted exclusively from the viral particles, isolated on a sucrose gradient, was amplified with a Pan-retrovirus PCR technique able to detect a conserved fragment in the Reverse transcriptase across different retroviral genera. To avoid any other source of contamination, we made sure that the cells' nuclei were removed before layering on the sucrose gradient. DNA sequencing confirmed the presence in the giant viruses of retroviral genes. A Pol-like region, spanning the most conserved 
domains VLPQG and YMDD of the Reverse Transcriptase, was detected. In addition, the isolated human giant viruses showed the Reverse transcriptase activity.

Another amplicon, aligning entirely on the chromosome 7, clustered with HERVs genes. This finding replicates consolidated evidence of chromosomal assignment and expression of full-length human endogenous retroviruses found on the chromosome $7^{17-24}$. Our results also confirm that these human Retro-Giant viruses have a $\mathrm{T}$ tropism after their isolation from human $\mathrm{T}$ cell leukemia. This raises some implications about their possible oncogenic role.

The $\mathrm{T}$ tropism of the Retro-Giant viruses relies on their retroviral nature, however, it is very improbable, as recently described ${ }^{25}$, to find DNA mimiviruses in human T lymphocytes. Nevertheless, the discovery of the retro-giant viruses was made, not only because of their ability to bind the anti-FeLV antibodies, but also for fundamental elements that we took from the discovery of the amoebas giant mimiviruses in 2003². How could we conceive the possibility of colouring the retro-giant viruses with the Gram staining without the previous discovery of mimiviruses in the amoeba? Our $400 \mathrm{~nm}$ particles would have been erroneously perceived as giant vesicles and not as gram positive giant viruses. With the Retro-Giants, the concept of giant virus is applied for the first time to the dogmas of retrovirology.

The Retro-Giant viruses represent a unique viral entity that suggests that defective retroviruses were possibly not sufficient for replication and required the interchange of genetic information with giant viruses' large biosynthetic assortment.

It follows by viewing our human Retro-Giant virus as a system that evolved from ancestral viruses to surround and shuttle retroviruses, providing a wider pathway for their dissemination. The 'viral factories' and viral histone $\mathrm{H} 4$, described in our previous study, suggests a protected system that hijacks host immunity and epigenetics to enhance viral replication.

The fact that the Retro-Giants can be detected with an anti-FeLV gag is simply an amusing co-incidence that must be addressed with additional proteomic and genetic analyses. It might be that prototypical leukaemia viruses were the first organisms to put these fragments of evolving protein machinery together to make something useful shared among ancient retroviruses. Feline retroviruses share conserved ancestral epitopes among different mammalian retroviruses ${ }^{26-31}$. In addition, the presence of a shared 5'-leader sequence in ancestral human and mammalian retroviruses and its transduction into Feline Leukemia virus has been recently documented ${ }^{32}$. In conclusion, we report not an archetypal human retrovirus nor even a large human retrovirus, but a human giant virus, Mimivirus-like, with an ancestral mammalian retroviral core. Although sharing some morphological features with Mimiviruses (i.e. gigantic size, the ability to retain Gram staining and viral factories), this human Retro-giant virus differs substantially from the DNA-amoebal giant viruses for its unique presence of mammalian retroviral genes (gag-pol). For this discovery we chose traditional techniques adopted by other microbe hunters during their viral discoveries. However, a whole genome shotgun sequence, a full reconstruction of the viral genome and a robust phylogenetic analysis are absolutely required to establish the complete structure and the evolutionary age of the Retro-Giant viruses.

\section{Conclusion}

The unusual features of the Retro-Giant viruses challenge our current concepts of retrovirology and the Retro-Giants will not have an easy life. It is difficult to accept the concept of viruses being giant, but it becomes almost unbearable when the giants are Retro-Giants.

"What? A giant virus, mimivirus-like, with a retroviral core? If they are so gigantic, why has nobody seen them before?" How to accept the provocative idea that the Retro-Giant viruses, could be ancestral creatures evolved earlier than archetypal retroviruses, as suggested by our preliminary phylogeny analysis on the most conserved VLPQG -YMDD region of the Reverse Transcriptase? These kind of questions reveal how complex scientific processes shape contemporary medical discoveries and their reception.

The giant mimiviruses in the amoeba are prehistorical creatures, evolved millions of years ago, since the dawn of evolution of eukaryotic cells $\mathrm{s}^{33,34}$. They are gigantic, yet nobody saw them until $2003^{2}$.

For the discovery of the Retro-Giant viruses, their retroviral nature, their ability to bind a screen of antibodies anti-Feline retroviruses and some of the biochemical properties of giant viruses proved to be lucky.

Not archetypal retroviruses, but Gram positive ancestral giant viruses, Mimivirus-like, with associated viral factories and a retroviral core: this is the essence of the human Retro-Giants that were missing.

\section{Data availability}

All slides and EM grids are available to be examined; please contact the corresponding author.

F1000Research: Dataset 1. 150 bp amplicon alignment against other VLPQG-YMDD Pol sequences of different retroviruses. DOI, 10.5256/f1000research.15118.d208073 ${ }^{12}$

F1000Research: Dataset 2. 400bp amplicon sequence and its alignment against other retroviral families. DOI, 10.5256/ f1000research.15118.d208074 ${ }^{13}$

F1000Research: Dataset 3. Uncropped and unedited blots. DOI, 10.5256/f1000research.15118.d208075 35

\section{Competing interests}

No competing interests were disclosed. 
Grant information

This work was supported in part by St Vincent Health Care Group of Dublin, Ireland.

The funders had no role in study design, data collection and analysis, decision to publish, or preparation of the manuscript.

\section{Acknowledgements}

The anti-FeLV-related moAbs were kindly provided as a gift by Dr Chris Grant of Custom Monoclonals International (West Sacramento, CA 95691, USA).

We thank Microgem Laboratory Research (Napoli, Italy) for their technical assistance.
1. Lusi EA, Maloney D, Caicci F, et al.: Questions on unusual Mimivirus-like structures observed in human cells [version 1; referees: 2 approved]. F1000Res. 2017; 6: 262. PubMed Abstract | Publisher Full Text | Free Full Text

2. La Scola B, Audic S, Robert C, et al.: A giant virus in amoebae. Science. 2003; 299(5615): 2033

PubMed Abstract | Publisher Full Text

3. Yamada T: Giant viruses in the environment: their origins and evolution. Curr Opin Virol. 2011; 1(1): 58-62.

PubMed Abstract | Publisher Full Tex

4. Van Etten JL, Lane LC, Dunigan DD: DNA viruses: the really big ones (giruses). Annu Rev Microbiol. 2010; 64: 83-99. PubMed Abstract | Publisher Full Text | Free Full Text

5. Claverie JM, Ogata $\mathrm{H}$, Audic $\mathrm{S}$, et al: Mimivirus and the emerging concept of “giant" virus. Virus Res. 2006; 117(1): 133-44. PubMed Abstract | Publisher Full Text

6. Raoult D, Audic S, Robert C, et al:: The 1.2-megabase genome sequence of Mimivirus. Science. 2004; 306(5700): 1344-50. PubMed Abstract | Publisher Full Text

7. Campos RK, Boratto PV, Assis FL, et al.: Samba virus: a novel mimivirus from a giant rain forest, the Brazilian Amazon. Virol J. 2014; 11: 95. PubMed Abstract | Publisher Full Text | Free Full Text

8. Thomas V, Bertelli C, Collyn F, et al:: Lausannevirus, a giant amoebal virus encoding histone doublets. Environ Microbiol. 2011; 13(6): 1454-66. PubMed Abstract | Publisher Full Text

9. Hepat R, Song JJ, Lee D, et al.: A viral histone h4 joins to eukaryotic nucleosomes and alters host gene expression. $J$ Virol. 2013; 87(20): 11223-30. PubMed Abstract | Publisher Full Text | Free Full Text

10. Poiesz BJ, Ruscetti FW, Gazdar AF, et al:: Detection and isolation of type C retrovirus particles from fresh and cultured lymphocytes of a patient with cutaneous T-cell lymphoma. Proc Natl Acad Sci U S A. 1980; 77(12): 7415-9. PubMed Abstract | Publisher Full Text | Free Full Text

11. Tuke PW, Perron $\mathrm{H}$, Bedin $\mathrm{F}$, et al: Development of a pan-retrovirus detection system for multiple sclerosis studies. Acta Neurol Scand Suppl. 1997; 169: $16-21$.

PubMed Abstract | Publisher Full Text

12. Lusi EA, Caicci F: Dataset 1 in: Discovery and description of the first human Retro-Giant virus. F1000Research. 2018. Data Source

13. Lusi EA, Caicci F: Dataset 2 in: Discovery and description of the first human Retro-Giant virus. F1000Research. 2018. Data Source

14. Perron H, Garson JA, Bedin F, et al.: Molecular identification of a novel retrovirus repeatedly isolated from patients with multiple sclerosis. The Collaborative Research Group on Multiple Sclerosis. Proc Natl Acad Sci U S A. 1997: 94(14): 7583

PubMed Abstract | Publisher Full Text | Free Full Text

15. Donehower LA, Bohannon RC, Ford RJ, et al:: The use of primers from highly conserved pol regions to identify uncharacterized retroviruses by the polymerase chain reaction. $J$ Virol Methods. 1990; 28(1): 33-46. PubMed Abstract | Publisher Full Text

16. Shih A, Misra R, Rush MG: Detection of multiple, novel reverse transcriptase coding sequences in human nucleic acids: relation to primate retroviruses. $J$ Virol. 1989; 63(1): 64-75. PubMed Abstract | Free Full Text

17. Reus K, Mayer J, Sauter M, et al:: Genomic organization of the human endogenous retrovirus HERV-K(HML-2.HOM) (ERVK6) on chromosome 7. Genomics. 2001; 72(3): 314-20. Genomics. 2001; 72(3): 314-20.
PubMed Abstract | Publisher Full Text

18. Mayer J, Sauter M, Rácz A, et al:: An almost-intact human endogenous retrovirus K on human chromosome 7. Nat Genet. 1999; 21(3): 257-8.

PubMed Abstract | Publisher Full Text
19. Tönjes RR, Czauderna F, Kurth R: Genome-wide screening, cloning, chromosomal assignment, and expression of full-length human endogenous retrovirus type K. J Virol. 1999; 73(11): 9187-95. PubMed Abstract | Free Full Text

20. Alliel PM, Périn JP, Goudou D, et al.: The HERV-W/7q family in the human genome. Potential for protein expression and gene regulation. Cell $\mathrm{Mol}$ Biol(Noisy-le-grand). 2002; 48(2): 213-7. PubMed Abstract

21. Yu H, Liu T, Zhao Z, et al.: Mutations in 3'-long terminal repeat of HERV-W family in chromosome 7 upregulate syncytin-1 expression in urothelial cel carcinoma of the bladder through interacting with c-Myb. Oncogene. 2014; 33(30): 3947-58.

PubMed Abstract | Publisher Full Text

22. Mayer J, Stuhr T, Reus K, et al.: Haplotype analysis of the human endogenous retrovirus locus HERV-K(HML-2.HOM) and its evolutionary implications. $J \mathrm{MO}$ Evol. 2005; 61(5): 706-15. PubMed Abstract | Publisher Full Tex

23. Weiss RA, Stove JP: Virology. Our viral inheritance. Science. 2013; 340(6134): $820-1$

PubMed Abstract | Publisher Full Text

24. Bock M, Stoye JP: Endogenous retroviruses and the human germline. Curr Opin Genet Dev. 2000; 10(6): 651-5.

PubMed Abstract | Publisher Full Text

25. Abrahão J, Silva $\mathrm{L}$, Oliviera $\mathrm{D}$, et al.: Lack of evidence of mimivirus replication in human PBMCs. Microbes Infect. 2018; 20(5): 281-283. PubMed Abstract | Publisher Full Text

26. Donner L, Fedele LA, Garon CF, et al:: McDonough Feline sarcoma virus: characterization of the molecularly cloned provirus and its feline oncogene (v-fms). J Virol. 1982; 41(2): 489-500. PubMed Abstract | Free Full Text

27. Sherr CJ, Fedele LA, Benveniste RE, et al:: Interspecies antigenic determinants of the reverse transcriptases and $\mathbf{p} 30$ proteins of mammalian type $\mathrm{C}$ viruses. $J$ Virol. 1975; 15(6): 1440-8. PubMed Abstract | Free Full Text

28. Geering G, Aoki T, Old LJ: Shared viral antigen of mammalian leukaemia viruses. Nature. 1970; 226(5242): 265-266 PubMed Abstract | Publisher Full Text

29. Ishida T, Pedersen NC, Theilen GH: Monoclonal antibodies to the v-fes product and to feline leukemia: virus P27 interspecies-specific determinants encoded by feline sarcoma viruses. Virology. 1986; 155(2): 678-87. PubMed Abstract | Publisher Full Text

30. Davis J, Gilden RV, Oroszlan S: Multiple species-specific and interspecific antigenic determinants of a mammalian type C RNA virus internal protein Immunochemistry. 1975; 12(1): 67-72.

PubMed Abstract | Publisher Full Tex

31. Wünsch M, Schulz AS, Kock W, et al.: Sequence analysis of Gardner-Arnstein feline leukaemia virus envelope gene reveals common structural properties of mammalian retroviral envelope genes. EMBO J. 1983; 2(12): 2239-2246. PubMed Abstract | Free Full Text

32. Kawasaki J, Kawamura M, Ohsato Y, et al.: Presence of a Shared 5'-Leader Sequence in Ancestral Human and Mammalian Retroviruses and Its Transduction into Feline Leukemia Virus. J Virol. 2017; 91(20): pii: e00829-17. PubMed Abstract | Publisher Full Text | Free Full Text

33. Moreira D, López-García P: Evolution of viruses and cells: do we need a fourth domain of life to explain the origin of eukaryotes? Philos Trans $R$ Soc Lond $B$ Sci. 2015; 370(1678): 20140327.

PubMed Abstract | Publisher Full Text | Free Full Text

34. Forterre $\mathrm{P}$, Gaïa M: Giant viruses and the origin of modern eukaryotes. Cur Opin Microbiol. 2016; 31: 44-9. PubMed Abstract | Publisher Full Text

35. Lusi EA, Caicci F: Dataset 3 in: Discovery and description of the first human Retro-Giant virus. F1000Research. 2018. Data Source 


\section{Open Peer Review}

\section{Current Peer Review Status: ?}

\section{Version 1}

Reviewer Report 13 July 2018

https://doi.org/10.5256/f1000research.16470.r35746

(c) 2018 Raoult D. This is an open access peer review report distributed under the terms of the Creative Commons Attribution License, which permits unrestricted use, distribution, and reproduction in any medium, provided the original work is properly cited.

\section{Didier Raoult}

Institut Hospitalo-Universitaire Méditerranée-Infection, Faculté de médecine, Aix-Marseille Université, URMITE, UM63, CNRS7278, IRD198, Inserm 1095, Marseille, France

\section{To authors}

This work reports the description of a giant virus with cross-reactivity and genes in common with retroviruses. The authors propose to describe the first giant retrovirus obtained from human cells. This work is very preliminary, and it is unfortunate not to have the complete genome of this virus. The reviewer is very supportive of this preliminary work. However, he thinks that, at least, the RNA polymerase sequence of the giant viruses, for which there are primers that have been described for mimiviridae, would be added, which would give a much higher value to this paper.

All in all, this is a work that can attract the attention of the scientific community to an interesting emerging hypothesis.

Is the work clearly and accurately presented and does it cite the current literature? Yes

Is the study design appropriate and is the work technically sound? Partly

Are sufficient details of methods and analysis provided to allow replication by others? Yes

If applicable, is the statistical analysis and its interpretation appropriate? Partly

Are all the source data underlying the results available to ensure full reproducibility? Yes 
Are the conclusions drawn adequately supported by the results?

Partly

Competing Interests: No competing interests were disclosed.

I confirm that I have read this submission and believe that I have an appropriate level of expertise to confirm that it is of an acceptable scientific standard, however I have significant reservations, as outlined above.

Author Response 17 Jul 2018

Elena Angela Lusi, University College Dublin, Dublin, Ireland

Dear Prof Raoult,

Thank you for taking the time to review my manuscript. Your suggestions are well received and greatly appreciated. I expect to have the genome sequenced in a few weeks.

What I have accomplished so far in the characterization of this human Retro-Giant virus is :

1. Isolation of the giant viral particles from human T cell leukaemia;

2. Electron Microscopy immunogold of the giant viruses with a screen of anti-FeLV retroviruses Abs;

3. Gram stain of the viral pellet;

4. Amplification of the VLPQ-YMDD region of RT transcriptase gene from the RNA of the giant viruses;

5. Reverse Transcriptase activity of the giant viral particles;

all of which I believe to be of a great significance.

I have also completed the proteomics analyses of the isolated viral particles. Retroviral as well as giant viruses peptides were confirmed. One of the identified retroviral peptides has oncogenic properties.

I will provide you with additional data once this last round of experiments has been completed.

Might these Retro-Giants be the ancestors of archetypal retroviruses? That is the question and an interesting scenario in retrovirology.

Your discovery of the Giant Viruses and my finding of human Retro-Giant viruses seem to be consistent with Howard Temin's views.

Best Regards

Elena Angela Lusi

Competing Interests: No competing interests. 
Elena Angela Lusi, University College Dublin, Dublin, Ireland

Dear Prof Raoult,

As per your request, please find the results of the whole genome sequence attached in the revised manuscript.

With this shotgun sequencing I can confirm the discovery of a human Retro-Giant in human T cells leukaemia.

This human virus is not a classic retrovirus, but a Gram positive Giant Virus, Mimivirus-like, with a unique mammalian transforming retroviral core and a T cells tropism.

The ORFs indicated in yellow are the retroviral core genes.

The presence of leukaemogenic retroviral sequences confirms the numerous repeats of the EM immmunogold, the documented retroviral antigenicity, the preliminary PCR results and reverse transcriptase activity of the giant viral particles.

The viral genome and the morphological analyses show the peculiar features of this giant microbial entity that is expression of a fascinating synthesis between archaea, prokaryotes and giant viruses. In some aspects, this human giant virus is more similar to an archaea than to a virus, even though the viral apparatus is well present.

We are facing ancestral creatures with a retroviral nature. The Retro-Giant Viruses are possibly the expression of the transition from the RNA to DNA world.

This discovery may even change our perspective in retrovirology and the way we conceive retroviruses. Not the basic gag-pol-env backbone and the small dimension anymore, but Gram positive giant particles with prokaryotes features and retroviral genes related to mammalian oncogenic retroviruses.

Just observe and consider Temin's last diagram in his Nobel address. He shows that a normal non carcinogenic avian virus interacts with something in human cell to create Rous Sarcoma Virus. He also suspected an ancestor for the Reverse Transcriptase.

I have assumed that most phylogenies are hypotheses and are based on indirect evidence. However, your discovery of Giant Viruses and my Retro-Giants could be that something I suspect Temin would think. Phylogeny is sometimes shield against the darkness, but our findings may have melted these shields.

A part from the fact that the Retro Giant viruses are ancestral to retroviruses, as a medical doctor working with people, I point to their leukaemogenic role. This really matters. We could isolate constantly the Retro-Giants form acute human T cells leukaemia just with a routine sucrose gradient. Every time, in every replicate fulfilling some of the Koch's postulates. 
The Retro-Giant viruses have oncogenic retroviral genes. Actions to eradicate leukaemogenic retroviruses are currently not possible, but targeting the constant presence of the ancestors may provide a new methodology.

We can not ignore the presence of the Retro-Giants, their oncogenes and their presence in human leukaemia. Science seek truths and patients need a diagnosis and treatment.

The concept of human giant viruses with prokaryotes features and an oncogenic retroviral core is not an easy one.

Fundamental elements and concepts of your discovery of the Giant Viruses helped me in understanding that this time we were facing exceptional ancestral creatures where prototypical leukaemia viruses were the first organisms to put together fragments of an evolving protein machinery shared among ancient retroviruses, archaea and prokaryotes.

The Retro-Giant viruses confirm Temin's prediction and, despite their prokaryotes and giant viruses features, they should be included in the current classification of retroviruses because their oncogenic retroviral genes may be the ones responsible for some types of human leukaemia.

Best Regards

Elena Angela Lusi

Competing Interests: No competing interests were disclosed.

The benefits of publishing with F1000Research:

- Your article is published within days, with no editorial bias

- You can publish traditional articles, null/negative results, case reports, data notes and more

- The peer review process is transparent and collaborative

- Your article is indexed in PubMed after passing peer review

- Dedicated customer support at every stage

For pre-submission enquiries, contact research@f1000.com

F1000Research 